\title{
Charging/discharging process for electric vehicles: proposal and emulation
}

\author{
M. Barnola-Sampera, D. Heredero-Peris, R. \\ Villafafila-Robles, D. Montesinos-Miracle, J. Bergas- \\ Jane
}

Centre d'Innovació Tecnològica en Convertidors Estàtics i Accionaments (CITCEA-UPC), Departament d'Enginyeria Elèctrica, Universitat Politècnica de Catalunya BarcelonaTech, ETS d'Enginyeria Industrial de Barcelona, Av. Diagonal, 647. 2nd floor - 08028 Barcelona, Spain

\begin{abstract}
This paper proposes a charging/discharging process for electric vehicles according to mode 4 , specifically based on the CHAdeMO protocol. These initiatives will enable acceptably fast charging of EVs. The proposal has been designed and implemented within the Endesa Novare Vehicle to Microgrid project. As a first stage of the project, the charge/discharge process has been emulated before it will be developed in a real device. The emulation consists of two main parts: (i) an electric vehicle and its battery management system emulated by a microcontroller, and (ii) a charging/discharging device emulated by a computer application. Both parts communicate via CAN bus as it is done in existing protocols. The proposed control flow for charging and discharging and the results of the emulation are presented. Moreover, in order to be able to manage charge and discharge processes according to power network operator, a data model for both electrical vehicle and charging/discharging device according to standard IEC 61850-7-420 is also proposed.
\end{abstract}

Keywords-Conductive charging/discharging, electric vehicles, emulation, V2G

\section{INTRODUCTION}

The presence of the electric vehicles (EVs) in the transportation system is growing steadily as alternative to conventional fueled vehicles. In fact, almost all manufacturers are working in this direction, waiting for a massive demand in the automobile market in coming years. The integration of EVs in electric power systems poses new challenges in terms of infrastructures, regulation and business models [1].

European projects such as 'Grid for Vehicles' (G4V) [2], 'Mobile Energy Resources in Grids of Electricity' (MERGE) [3], 'Active Distribution networks with full integration of Demand and distributed energy RESourceS' (ADDRESS) [4] or 'Green eMotion' [5] are developing the framework for an interoperable electrical mobility system.

According to the results from these initiatives, new agents in charge of developing the infrastructure and providing charging services will be introduced. The aggregator, as a new agent, appears to collect the demands of a number of EVs and offer demand side management of this aggregated group of EV to the The authors acknowledge the support received from Endesa through Novare Awards for developing this research project

\author{
N. Vidal-Tejedor \\ Endesa, Research, Technology Development and Innovation \\ Av. Vilanova, 12 - 08018 Barcelona, Spain
}

market [6]. All this architecture will need an infrastructure of information and communications technologies within the various parties.

Fig. 1 illustrates a general scheme of this architecture. EV requires both an electrical connection and communications link with the utility and all processes must be completely safe for both the user and the vehicle at all times. With an important role, the Battery Management System (BMS) communicates with the charging/discharging device in order to manage the battery, monitor its state, balance cells or report data. In addition, in order to take control of the process, it will be necessary to maintain communication upstream to the charging/discharging device.

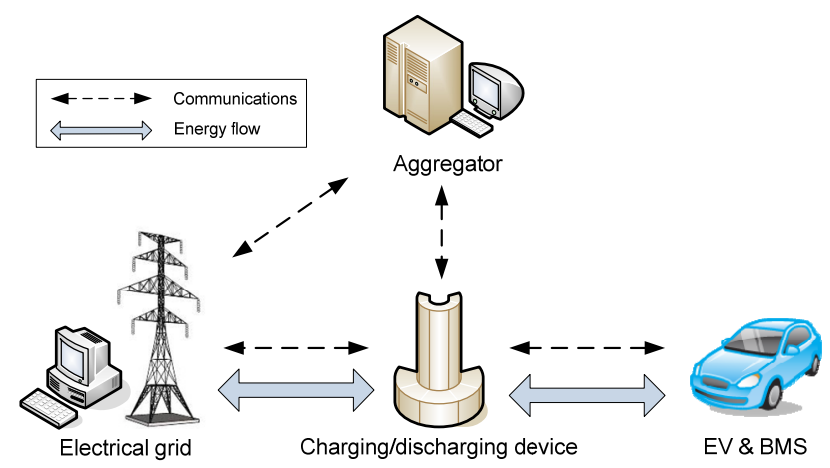

Fig. 1. Conceptual framework of the EV's

EVs are parked most of the time, so it will be possible to use them as energy storage devices. With a demand side management, the vehicles can charge their batteries during time lapses of excess of renewable electricity generation and are also able to inject energy to the grid in hours of high electricity demand or improve power quality by acting as active filters. This concept, known as Vehicle-to-Grid (V2G), requires a bidirectional power flow between the EV and the grid for charging/discharging process. There is much literature about this architecture [7], [8]. The exchange of information between 
the charging/discharging device and the BMS is essential to ensure the control of the charging process and the future implementation of V2G. However, while the international standards define different charging modes [9], the standards of discharging modes are ongoing.

In this sense, this paper proposes the operating sequence for both charging and discharging process for EVs and develops an interface of emulation in order to evaluate their proper operation in various scenarios without using real charging/discharging device nor EV. It is expected that both the emulation platform and the sequence flow proposed in this paper, can be the basis for defining a standard for the charge/discharge of EVs with a real energy flow.

In the following sections, the paper introduces the charging modes. Then, it describes the tools used to implement the emulation of a charging/discharging process for EVs and how it has been implemented. This emulation is tested and the results will be analyzed. Finally, the paper also proposes a solution to communicate the charger/discharger upstream to the electrical grid.

\section{REVIEW OF CHARGING MODES}

The batteries of electric vehicles can be charged by using conductive charging systems [9] and inductive charging systems [10]. The former option is mainly deployed. Part 1 of international standard IEC 61851 describes four conductive charging modes for EV [9]:

- Mode 1: AC charging from a household-type socket and extension wire.

- Mode 2: AC charging from a household-type socket with an in-cable protection device.

- Mode 3: AC charging using a specific EV plug with control and protection function installed.

- Mode 4: DC charging using an off-board charging device.

Modes 1, 2 and 3 refer to on-board chargers so AC to DC conversion is done inside the vehicle.

The international standard IEC 62196 describes a panel of plugs and sockets for conductive charging of EVs via mode 3 [11]. According to this standard, three plug types are defined: (1) single phase vehicle coupler (2) single and three phase vehicle coupler and (3) single and three phase vehicle coupler equipped with safety shutters.

Modes 3 and 4 ensure the maximum security for users while allowing the control of the process. In this sense, several alliances in the automotive and electrical sectors have begun to develop systems with specific connectors with the combination of mode 3 and types 2 or 3 in order to charge the vehicles safely. In Europe, manufacturers are working according to the standard IEC 62196 [11], while USA works in accordance to the standard SAE J1772 [12].
Regarding mode 4 there is a protocol called CHAdeMO [13], which has been initially promoted by Japanese enterprises and some companies in other countries have joined it later. The CHAdeMO protocol permits a quick charging of the battery of electric vehicles, delivering up to $62.5 \mathrm{~kW}$ (up to $500 \mathrm{~V} \mathrm{DC}$ and $125 \mathrm{~A}$ ) of direct current via the special connector developed by TEPCO/JARI DC within the CHAdeMO association framework.

In order to ensure a safe and robust operation, this protocol uses analog and digital communication (via CAN bus) between the charging device and the EV using a specific connector. Such connector involves two power pins, four analog signal pins, two CAN digital signal pins, one ground pin. It includes an electrical and mechanical blockage system so that it does not become disengaged during charging operation, ensuring an electrical connection that cannot be interrupted by the user.

In order to control the charging/discharging processes and implement the V2G, mode 4 seems more convenient that mode 3 alternatives that require and on-board power converter [14] because it does not depend of the EV's manufacturer specifications and it facilitates the coordination of power system operators. The proposal of emulation, developed in this paper, is based on this mode 4 and CHAdeMO protocol.

\section{EMULATION OF CHARGING/DISCHARGING PROCESS}

The work that is presented in this paper has been developed within the Endesa Novare Vehicle to Microgrid project [15], where a V2G system has been developed and tested in a laboratory platform. As a first stage, the proposal for charging/discharging process is emulated. The emulation permits testing new developments reducing time of development in real devices and improving safety issues for equipment.

Here, the emulation consists of two parts:

- Emulation of EV \& BMS is performed using a microcontroller. It includes the battery charge/discharge curves. It is described in Section III-A.

- Emulation of charging/discharging device is performed using personal computer. It includes the Human Machine Interface (HMI) of the application. Also it can configure the initial conditions of the BMS. It is described in Section III-B.

Fig. 2 locates the emulation devices within the general framework of the EV's associated architecture. The sequences flows of the emulation process, that are described in Section IV, are programmed in the microcontroller and the computer application with multi-platform code $\mathrm{C}$, so it can be easily implemented in different platform environments.

An USB to CAN interface allows the communication between the CAN port of the module for the microcontroller and the USB port of the computer. All the information is transferred via CAN and no exchange of energy is implemented in the emulation. 


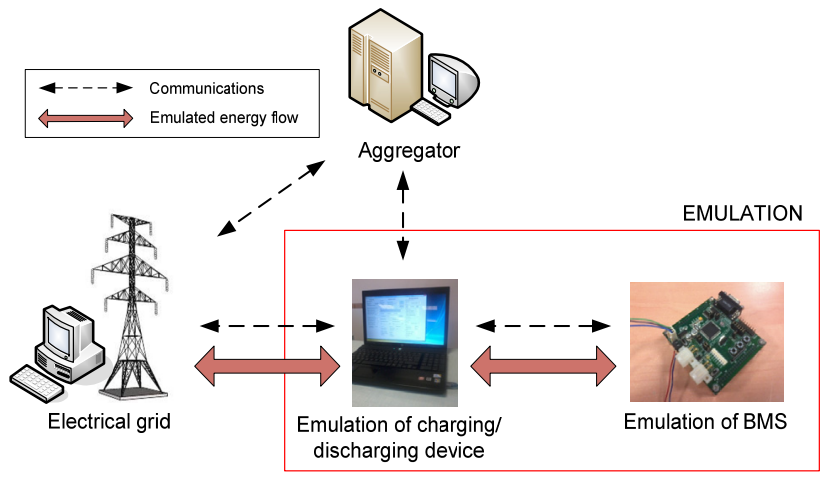

Fig. 2. Devices in the emulation

\section{A. Emulation of $B M S$}

This section describes the battery model used for dynamic simulation in order to obtain the charge/discharge curves. Then, these curves are tabulated in order to use them in the microcontroller software. To obtain points within the range simulated, the software of the microcontroller interpolates the values tabulated previously.

The modeling of a battery is a complex procedure and requires a thorough knowledge of electrochemistry. This paper is focused in the emulation of a charging/discharge process for EVs and the communications between parties, so the battery model doesn't require such a high level of precision. However, the proposed model can be used to represent the charge/discharge curves of the manufacturers with a similar behavior to reality.

The battery of the EVs is modeled using a controlled voltage source in series with a constant resistance [16]. This model assumes the same characteristics for the charge and the discharge cycles. The model is described by equations (1), (2) and (3).

$$
\begin{aligned}
& E=E_{0}-K \frac{Q}{Q-\int i_{b a t} d t}+A \cdot \exp (-B \\
& \left.\cdot \int i_{b a t} d t\right) \\
& V_{b a t}=E-R \cdot i_{b a t} \\
& \text { SOC }=100 \cdot\left(1-\frac{\int i_{b a t} d t}{Q}\right)
\end{aligned}
$$

where $E$ is the open circuit voltage $(V), E_{0}$ is battery constant voltage $(\mathrm{V}), \mathrm{K}$ represents polarization voltage $(\mathrm{V}), \mathrm{Q}$ is battery capacity (Ah), $\int \mathrm{i}_{\text {bat }} \mathrm{dt}$ describes the actual battery charge (Ah), $\mathrm{A}$ is the exponential zone amplitude $(\mathrm{V}), \mathrm{B}$ is the exponential zone time constant inverse (Ah)-1, Vbat is the battery voltage $(\mathrm{V}), \mathrm{R}$ is the internal resistance $(\Omega)$, ibat is battery current $(\mathrm{A})$ and, finally, SOC is the State of Charge (\%).

This model can reproduce the manufacturer's curves for the four major types of battery chemistries [16]. These four types are Lead-Acid, Lithium-Ion (Li-Ion), Nickel-Cadmium (NiCd) and Nickel-Metal-Hydride (NiMH). In this paper, the batteries of the vehicles Nissan Leaf and Mitsubishi i-MiEV, whose technology is Li-Ion, have been modeled. The batteries parameters have been extracted from the manufacturer's specifications [17]. The parameters found for both battery cells are presented in Table I. To simulate the complete battery, it is taken into account that the Mitsubishi i-MiEV has 88 cells in series, while the Nissan Leaf has 96x2 cells. Thus, the SOC and the battery voltage are simulated in various scenarios.

TABLE I. BATTERY CELLS PARAMETERS

\begin{tabular}{|c|c|c|c|}
\hline Parameter & Unit & Mitsubishi i-MiEV & Nissan Leaf \\
\hline $\mathbf{E}_{\mathbf{0}}$ & $\mathrm{V}$ & 3.7 & 3.8 \\
\hline $\mathrm{K}$ & $\mathrm{V}$ & 0.00876 & 0.00876 \\
\hline $\mathrm{Q}$ & $\mathrm{Ah}$ & 50 & 33.1 \\
\hline $\mathrm{A}$ & $\mathrm{V}$ & 0.468 & 0.468 \\
\hline $\mathrm{B}$ & $(\mathrm{Ah})-1$ & 3.5294 & 3.5294 \\
\hline $\mathrm{R}$ & $\Omega$ & 0.09 & 0.09 \\
\hline
\end{tabular}

Fig. 3.a and Fig. 3.b illustrate the evolution of the SOC at different charging currents for Mitsubishi i-MiEV and Nissan Leaf, respectively.

Fig. 3.c and Fig. 3.d illustrate the evolution of the SOC at different discharging currents for Mitsubishi i-MiEV and Nissan Leaf, respectively.
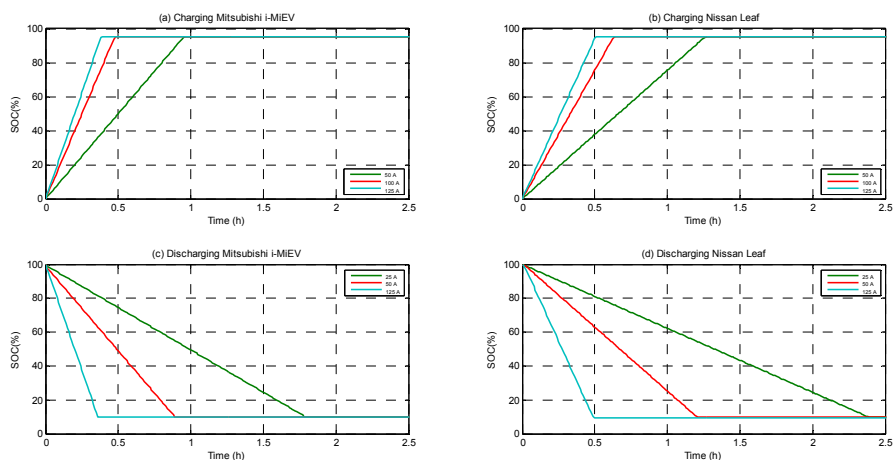

Fig. 3. Evolutions of SOC

This linearized model yields accurate results and also represents the behavior of the battery, but has some considerations such as: (i) the internal resistance is supposed constant during the process, (ii) the temperature doesn't affect the model's behavior, (iii) the self-discharge of the battery is not represented, and (iv) the battery has no memory effect. There are battery models reported in the literature with other considerations [18], but is not the scope of this paper.

\section{B. Emulation of charging/discharging device}

The emulation of charging/discharging device is performed using personal computer. This is managed through a HMI with eight blocks, as shows Fig. 4. Each block and the parallelism with the real process are described below. 


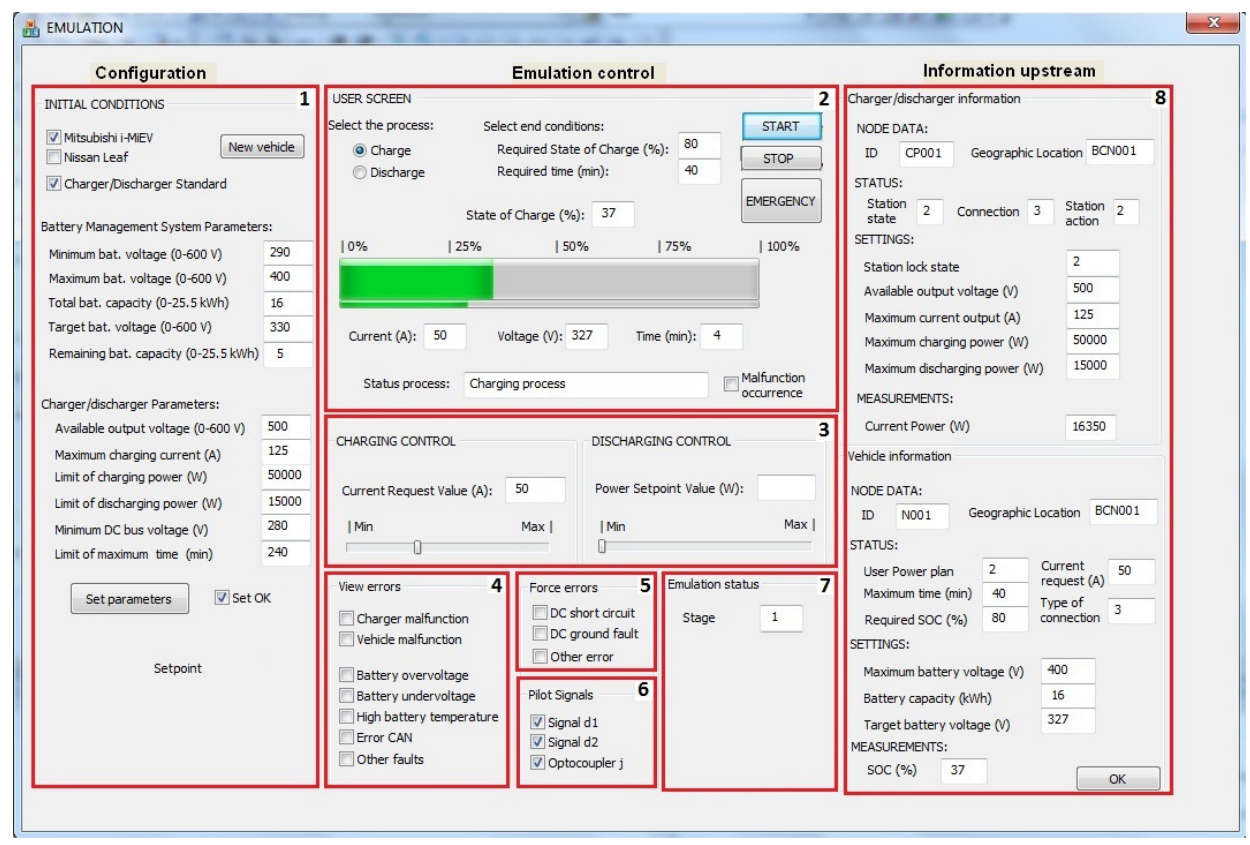

Fig. 4. HMI of the emulation

Configuration block (1): It permits to enter initial conditions defined by the BMS and the charging/discharging device features. The values can be initialized automatically, selecting the vehicle, or manually.

Emulation control blocks (2-7): Block 2 shows a proposal of screen which may be implemented in a charging/discharging real device. This screen permits some options such as to select the charger/discharger process, fix the end conditions (maximum time and SOC), push the process buttons or read information of the status of the process. Block 3 allows controlling the current request value during the charging process and the power setpoint value during the discharging process. Block 4 displays the possible errors occurring in the vehicle or the charger/discharger. Block 5 allows forcing errors during the process by the user of the emulation. Block 6 displays the analog signals associated with the charging/discharging device. Block 7 shows the general stage of the process.

Information upstream block (8): It shows the data transmitted from the charging/discharging device to third parties.

\section{CHARGING/DISCHARGING PROCESS}

In the CHAdeMO protocol, after a first procedure that includes an interchange of electrical parameters between the EV and the charger, the vehicle notifies the charger of the charging current requested. So, in charge mode, the EV plays the role of master and the charger is the slave. The vehicle and the charger monitor their conditions while charging. When end conditions are accomplished or any abnormality is detected, the supply of current shuts down with a prefixed current rate limits.
Based on this protocol, the proposals for charging and discharging sequence flows are described next.

\section{A. Charging sequence flow diagram}

The vehicle acts as a master. It notifies the charger of the charging current request value throughout the charging process. The charger sets the command value as the control target.

Fig. 5 shows the charging sequence in full. The power transfer and the pilot signals are emulated using additional messages in the CAN information. According to connector developed by TEPCO/JARI DC, Signal_k refers to charging enable/disable (pin 4), Signal_d1 refers to charger start/stop_1 (pin 2) and Signal d2 refers to charger start/stop 2 (pin $1 \overline{0}$ ). The control flow is divided in three parts that are described next:

Preparation for charging: when the user turns on the START button, the vehicle recognizes that the charging operation begins. Then, the BMS responds by transmitting the parameters of its battery via CAN. After the charger confirms this information, it transmits the charger parameters. The vehicle checks its compatibility and sends the permission signal (Signal_k, see Fig. 5) to start charging. After the connector is locked, the blockage is verified and when the insulation test is completed, the charging can start.

Exchange of power: the BMS calculates the current level based on battery needs. Such need can be changed, and sends the value to the charger every $100 \mathrm{~ms}$ through the CAN bus. The BMS and the charger monitor their conditions while charging. If an abnormality is detected by any part (EV or charger device), the supply of the current must be shut down.

End of charging: the vehicle sends to zero the current value using different rate limits and then the charger stops its output. 
After confirmation of zero current on the vehicle, it opens the EV contactor on the entrance of its battery system and sends a prohibition signal to the charger. Then, the charger confirms that its output current is zero, open the relays (Signal_d1 and Signal_d2, see Fig. 5) and unlock the connector.

The process can end for several reasons: end conditions accomplished, stop or emergency button pressed or vehicle/charger malfunction detected such as incorrect values, communication error, maximum time exceeded, etc. In all scenarios, the process is stopped controllably.

An emulation of this process is shown in Section V-A.

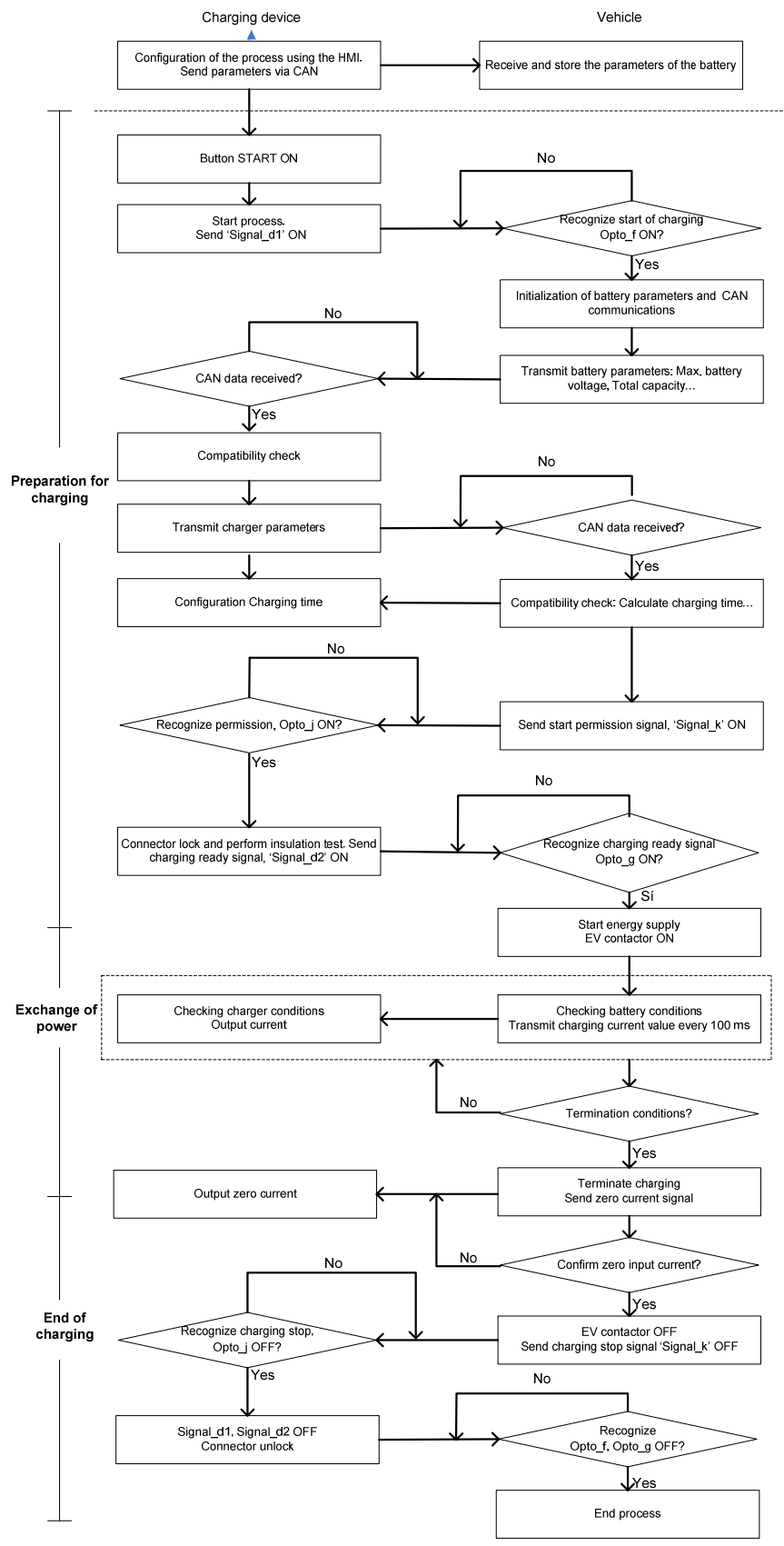

Fig. 5. Charging control flow

\section{B. Discharging sequence flow diagram}

The design of discharging process is based on the specifications of charging process. However, in this scenario the roles change. The discharging device plays the role of master and the EV is the slave but with EV power restrictions. In this situation, the requests come from upstream as a power set point.

The discharging process verifies if the devices are able to inject current to the grid or not. Moreover, the V2G capacity requires a change in the process management and the exchanged parameters. Fig. 6 shows the sequence flow that is described next.

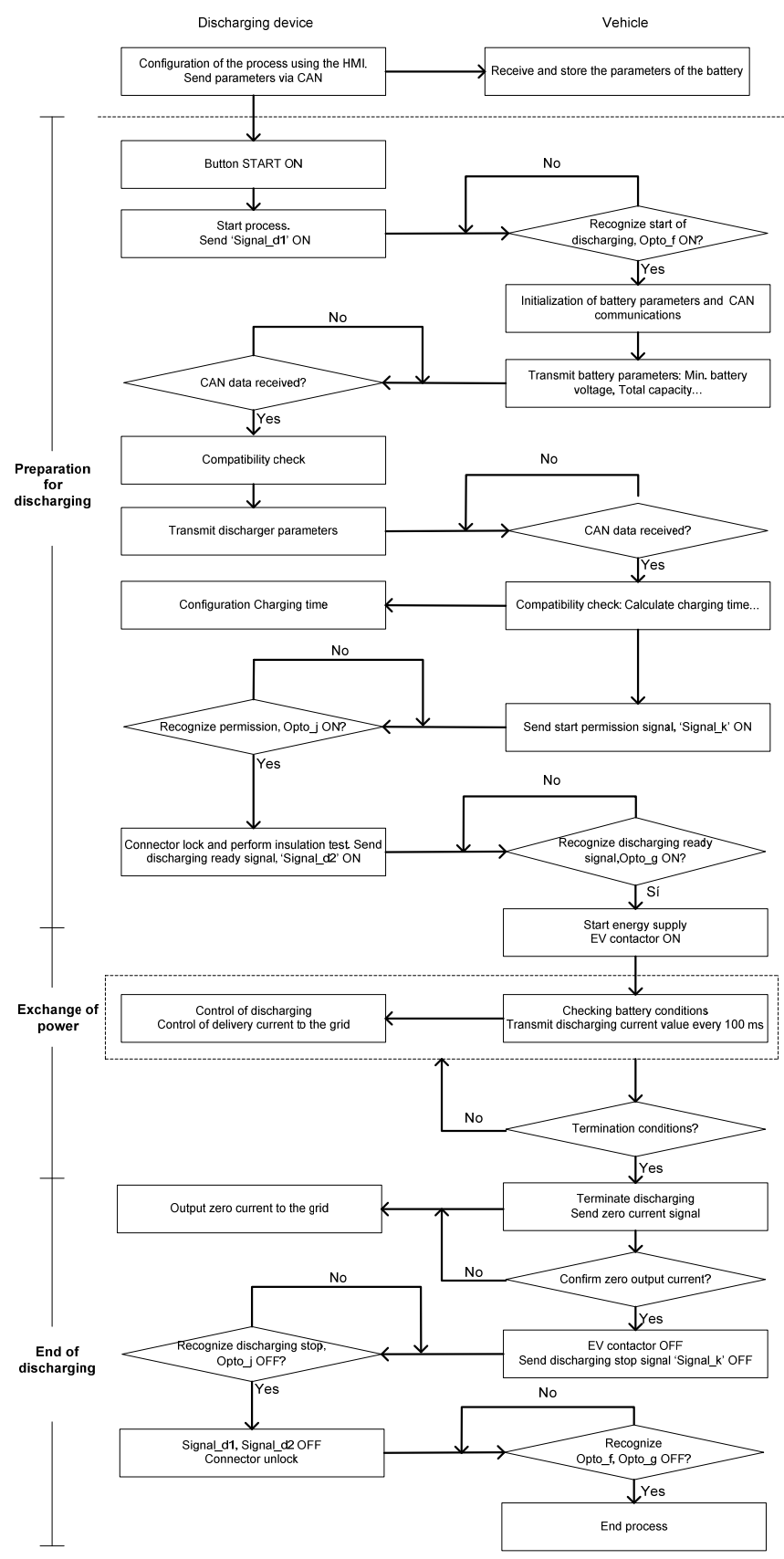

Fig. 6. Discharging control flow 
Preparation of discharging: after process is started, the BMS and the discharger transmit the parameters, check the compatibility of the process, lock the connector and prepare the discharging process.

Exchange of power: the BMS limits, repeatedly, the parameters according to the current conditions of the process in order to protect the battery. During the emulation the conditions can be changed via the emulation control of the HMI.

End of discharging: after the termination conditions are fulfilled, the current output is set to zero and the process ends controllably.

An emulation of this process is shown in Section V-B.

\section{RESUlts}

The devices of the emulation platform are programmed with the control flows described in previous section and the most representative parameters of the data transmitted through CAN bus is captured and plotted for three scenarios: (i) full charging, (ii) full discharging and (iii) interrupted charging. To properly interpret the results, it should be noted that one second in the emulation time is equivalent to one minute in a real process time.

\section{A. Full charging}

In the first scenario, a Mitsubishi i-MiEV charging is emulated. Initially, the SOC is $30 \%$ and at the end of the process the battery is charged up to $80 \%$, approximately. After preparation of charging, the BMS makes a current request of $50 \mathrm{~A}$ until the battery reaches the desired level of energy. The value of the current requested has been selected through the HMI. It is constant in this scenario. The battery voltage increases from 320 to $326 \mathrm{~V}$.

Fig. 7 shows the evolution of the current request from the BMS, the SOC of the battery and the battery voltage during this process.

Fig. 8 displays the signal pins ( $a, b$ and $c$ ) and the general stage of the process (d). The general stage plots the 'Preparation for charging' (0), 'Exchange of energy' (1) and 'End of charging' (2).

The signal pins exchange the control signals for charge start/stop and the charge permission/prohibition. They switch on or off state according to the sequence flow of the process (see Fig. 5). Thus, the exchange of energy occurs when the three pilot signals are on. After charging, the pilot signals switch off in a control way.

\section{B. Full discharging}

In this scenario, the test is effectuated during discharging of Nissan Leaf. The process starts with the SOC at $80 \%$ and finishes when the battery reaches to $50 \%$. The power set point requested from electrical grid, which is emulated with the HMI, has been modified and accordingly varies the value of the current request from 12 to $28 \mathrm{~A}$. The battery voltage decreases from 359 to $354 \mathrm{~V}$.

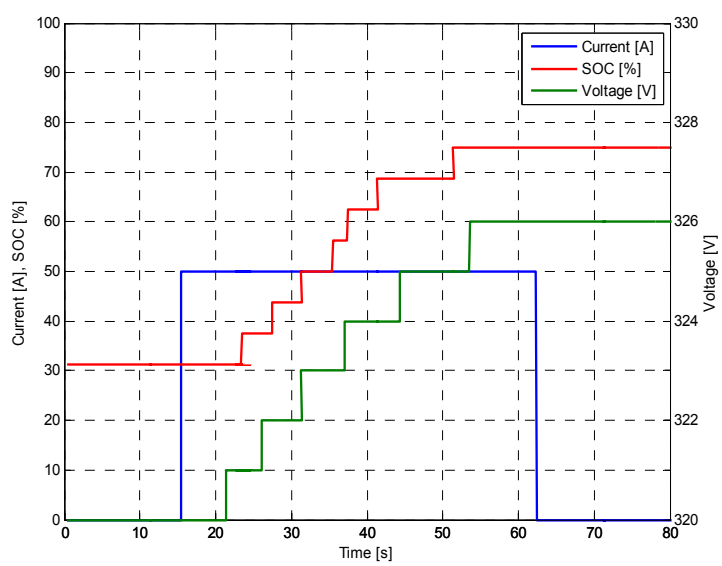

Fig. 7. Parameters of full charging

(a) Charging - Signal d1

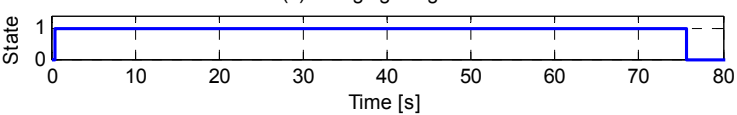

(b) Charging - Signal d2

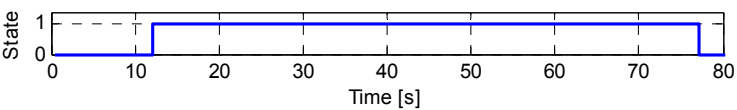

(c) Charging - Signal $\mathrm{k}$

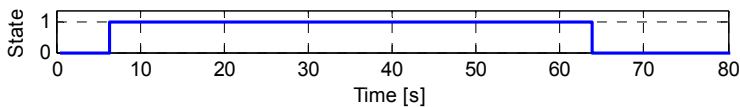

(d) Charging - General stage

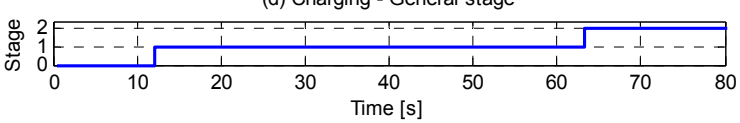

Fig. 8. Signals of full charging

Fig. 9 shows the evolution of the current request and the SOC of the battery.

After preparation of charging and the three signal pins are switched on, the general stage evolves to the exchange of energy until end conditions completed. Then, the signal pins switch off according to the discharging sequence flow of the process, see Fig. 6.

Fig. 10 displays the evolution of the state of the signal pins and the general stage.

\section{Interrupted charging}

In the third scenario, a charging process is interrupted due to malfunction occurrence. At the beginning of the process, the SOC is $40 \%$ and the battery is charged until a DC ground fault is forced through HMI.

Fig. 11 shows how the current request drops to zero when a malfunction is detected at $25 \mathrm{~s}$, approximately. The battery voltage increases from 320 to $321 \mathrm{~V}$.

Although a malfunction is detected during charging, the process is stopped in a control way. Fig. 12 displays how the Signal_k switches off and the general stage evolves to end of charging 
when the error is occurred. Signal_d1 and Signal_d2 also switch in a control way according to the sequence flow of the process.

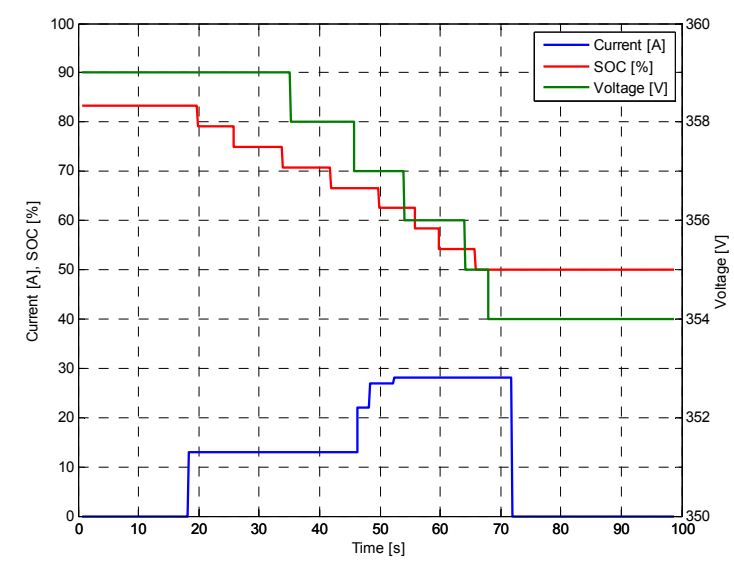

Fig. 9. Parameters of full discharging

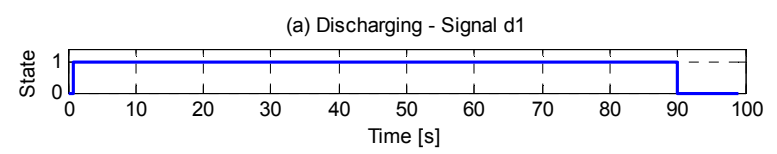

(b) Discharging - Signal d2

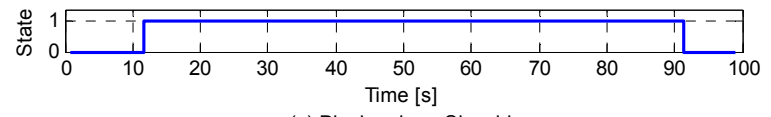

(c) Discharging - Signal $\mathrm{k}$

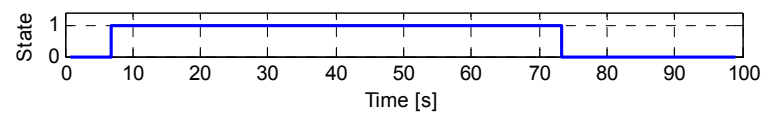

(d) Discharging - Stage

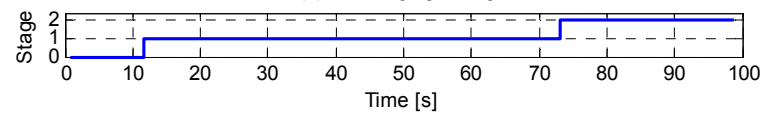

Fig. 10. Signals of full discharging

\section{UPSTREAM INFORMATION}

Due to the need of control charging/discharging processes, a communications between the charging/discharging device and the parties within the electricity supply network are needed. This section presents a solution based on the standard IEC 61850-7-420 [19].

The use of V2G will necessitate the communication of real time battery state and grid loading data. Thus, a two-way flow of communications will be sent from the charging/discharging device to upstream.

The standard IEC 61850-7-420 defines logical nodes (LN) that describe predefined groups of data objects (DO) that serve specific functions and can be used to build the complete device. The standard defines nodes for generation and storage devices, fuel cells, micro turbines, photo voltaic arrays, etc.

In this paper, a proposal is made to extend the standard with LNs for both the EVs and the charging/discharging device:
ZEVB and ZEVC, respectively. The proposed extensions are named according to the rules of the IEC 61850-7-420, where, $Z$ is for process/equipment level, $\mathrm{EV}$ for is electric vehicle, $\mathrm{B}$ is for battery and $\mathrm{C}$ is for charging/discharging device.

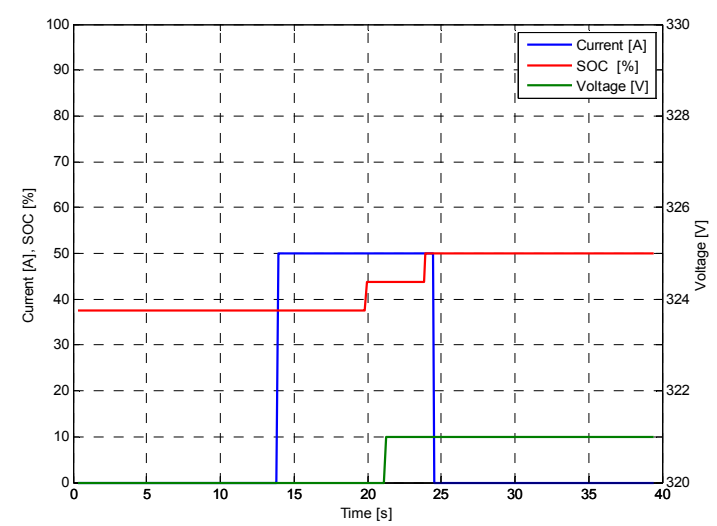

Fig. 11. Parameters of interrupted charging

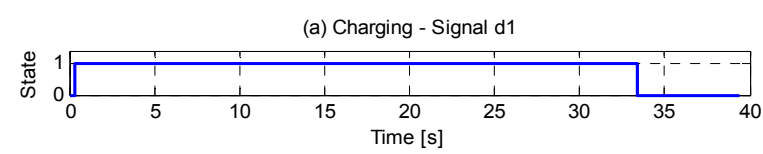

(b) Charging - Signal d2

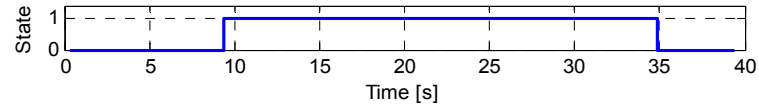

(c) Charging - Signal k

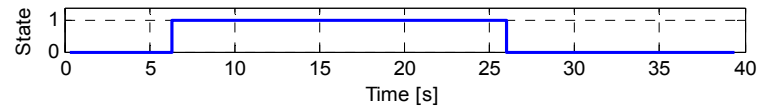

(d) Charging - Stage

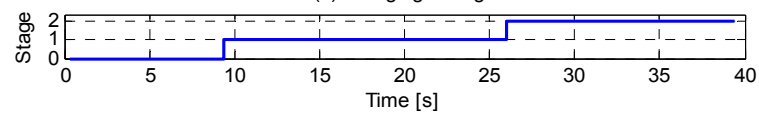

Fig. 12. Signals of interrupted charging

\section{A. Logical node for $E V$}

The logical node ZEVB, showed in Fig. 13, represents the EV's battery. This logical node defines a specific DO which describes the status of the $\mathrm{EV}$ and provides information on the location of the vehicle as well as user requirements. The structure of the DO is defined in the common data class according to the standard. The explanation defines the DO and how it is used. The T column indicates the transient DO. The $\mathrm{M} / \mathrm{O} / \mathrm{C}$ column indicates if the DO is mandatory, optional or conditional, respectively.

\section{B. Logical node for charger/discharger}

The logical node ZEVC, showed in Fig. 14, represents the EV's charger/discharger. This $\mathrm{LN}$ defines the electrical parameters and other useful information of this device.

\section{CONCLUSIONS}

In this paper, a charging/discharging process for electric vehicles with V2G capacity has been proposed and emulated. 
In order to perform tests without the real devices, this application allows the simulation of the behavior of an EV and a charging/discharging device and establishes communications between them.

\begin{tabular}{|c|c|c|c|c|c|}
\hline \multicolumn{6}{|c|}{ ZEVB Class } \\
\hline Data Object Name & $\begin{array}{c}\text { Common } \\
\text { Data Class }\end{array}$ & & Explanation & $\mathrm{T}$ & $\mathrm{M} / \mathrm{O} / \mathrm{C}$ \\
\hline LNName & & \multicolumn{2}{|c|}{$\begin{array}{l}\text { Shall be inherited from Logical-Node Class (see IEC } \\
61850-7-2 \text { ) }\end{array}$} & & \\
\hline \multirow{2}{*}{\multicolumn{6}{|c|}{ Data }} \\
\hline & & & & & \\
\hline & & \multicolumn{2}{|c|}{$\begin{array}{l}\text { LN Shall inherit all mandatory data from common logical } \\
\text { node classes }\end{array}$} & & M \\
\hline & & \multicolumn{2}{|c|}{ The data from LLN0 may optionally be used } & & $\mathrm{O}$ \\
\hline ID & UID & \multicolumn{2}{|c|}{ EV identifier } & & $\mathrm{M}$ \\
\hline GeoLoc & GEO & \multicolumn{2}{|c|}{ The geographic location of the EV } & & 0 \\
\hline \multicolumn{6}{|l|}{ Status information } \\
\hline \multirow[t]{6}{*}{ PlanSt } & \multirow[t]{6}{*}{ ENS } & \multicolumn{2}{|c|}{ Required EV Power Plan } & & \multirow{6}{*}{ M } \\
\hline & & Value & Explanation & & \\
\hline & & 0 & $\begin{array}{l}\text { Lxpowitalit } \\
\text { Unkown }\end{array}$ & & \\
\hline & & & Immediate Charging & & \\
\hline & & 2 & Immediate Discharging & & \\
\hline & & & Smart Charging & & \\
\hline DiscTime & INS & Maximum ti & ne of process (min) & & 0 \\
\hline ReqSOC & INS & Required S & $\mathrm{C}$ at the time of disconnection (\%) & & $\mathrm{O}$ \\
\hline ReqAmp & ASG & Current req & lest (A) & & $\mathrm{O}$ \\
\hline \multirow[t]{6}{*}{ ConnType } & \multirow[t]{6}{*}{ ENS } & \multicolumn{2}{|c|}{ Type of connection (Current) } & & \multirow{6}{*}{ M } \\
\hline & & Value & Explanation & & \\
\hline & & & Unknown & & \\
\hline & & & Single-Phase AC & & \\
\hline & & $\frac{1}{2}$ & Three-Phase AC & & \\
\hline & & 3 & DC & & \\
\hline \multicolumn{6}{|l|}{ Settings } \\
\hline MaxBatV & ASG & \multicolumn{2}{|c|}{ Maximum battery voltage $(\mathrm{V})$} & & 0 \\
\hline BatCap & ASG & \multicolumn{2}{|c|}{ Total battery capacity $(\mathrm{kWh})$} & & $\mathrm{M}$ \\
\hline BatV & ASG & \multicolumn{2}{|c|}{ Target battery voltage $(\mathrm{V})$} & & 0 \\
\hline \multicolumn{6}{|l|}{ Measurements } \\
\hline SOC & MV & \multicolumn{2}{|c|}{ State of charge $(\%)$} & & $\mathrm{M}$ \\
\hline
\end{tabular}

Fig. 13. Logical Node for EV

After studying the charging modes, sequence flows for charging/discharging processes are proposed in mode 4 . These sequences have been implemented in a microcontroller and a computer application and they had been made flexible to export them to other platforms.

During the processes, the information exchanged has been captured in order to plot the most representative parameters. The results obtained are according to the sequence flows designed in multiple possible scenarios.

Due to the need of communications upstream of the charging/discharging device, a two LN based on the standard IEC 61850-7-420 are proposed. Then, these LN are described to represent the EVs and the charging/discharging device and communicate them with the aggregator of the electrical grid.

\section{ACKNOWLEDGMENT}

The authors acknowledge the support received from Endesa through Novare Awards for developing this research project.

\section{REFERENCES}

[1] Tomás Gómez San Román, Ilan Momber, Michel Rivier Abbad, Álvaro Sánchez Miralles, "Regulatory framework and business models for charging plug-in electric vehicles: Infrastructure, agents, and commercial relationships", Energy Policy, Volume 39, Issue 10, October 2011.

[2] Project G4V, [http://www.g4v.eu], October 2012.

[3] Project MERGE, [http://www.ev-merge.eu], October 2012

[4] Project ADDRESS, [http://www.addressfp7.org], October 2012.

[5] Project Green eMotion, [http://www.greenemotion-project.eu], October 2012.

[6] Bessa, Ricardo J.; Matos, Manuel A.; "The role of an aggregator agent for EV in the electricity market," Power Generation, Transmission,
Distribution and Energy Conversion (MedPower 2010), 7th Mediterranean Conference and Exhibition on, pages 1-9, 7-10 Nov. 2010.

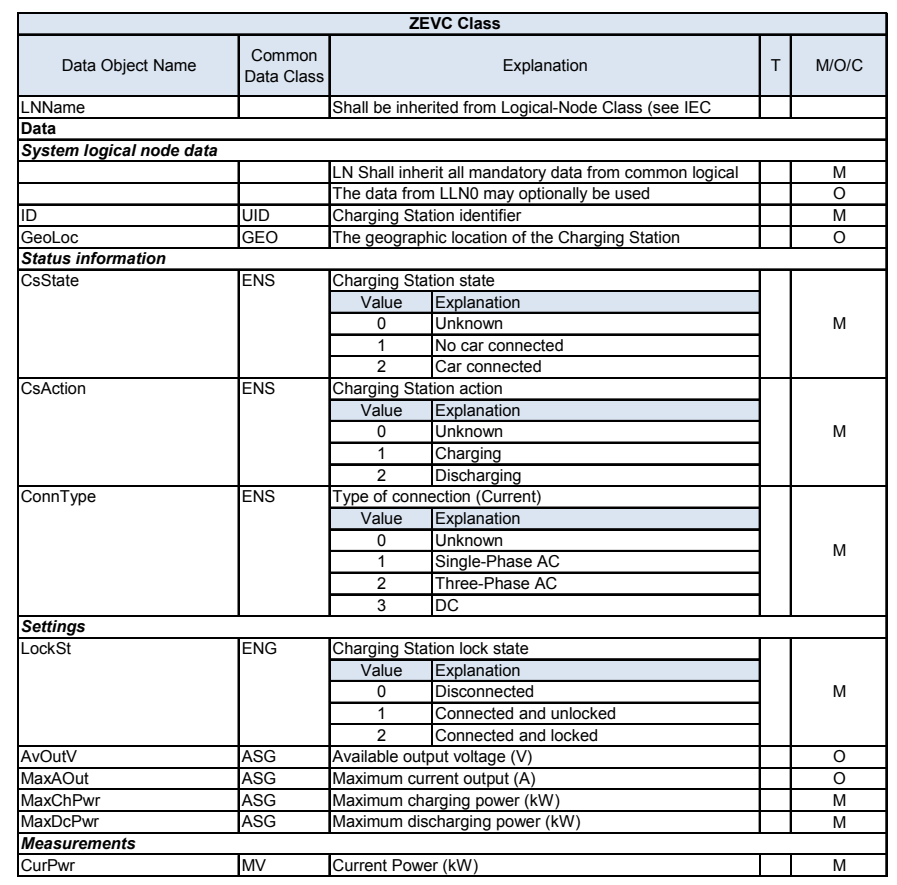

Fig. 14. Logical Node for charger/discharger

[7] Boulanger, A.G.; Chu, A.C.; Maxx, S.; Waltz, D.L.; "Vehicle Electrification: Status and Issues," Proceedings of the IEEE, vol.99, no.6, pp.1116-1138, June 2011.

[8] Guille, C.; Gross, G.; , "Design of a Conceptual Framework for the V2G Implementation," Energy 2030 Conference, 2008. ENERGY 2008. IEEE , vol., no., pp.1-3, 17-18 Nov. 2008

[9] IEC 61851. Electric vehicle conductive charging system.

[10] IEC 61980. Electric equipment for the supply of energy to electric road vehicles using an inductive coupling.

[11] IEC 62196-1. Plugs, socket-outlets, vehicle connectors and vehicle inlets - Conductive charging of electric vehicles.

[12] SAE Standards, [http://www.sae.org], September 2012.

[13] CHAdeMO Association, [http://www.chademo.com], September 2012.

[14] Yilmaz, M.; Krein, P.; "Review of Battery Charger Topologies, Charging Power Levels and Infrastructure for Plug-in Electric and Hybrid Vehicles," Power Electronics, IEEE Transactions on, vol.PP, no.99, pp.1,

[15] Villafafila-Robles, R.; Lloret-Gallego, P.; Heredero-Peris, D.; Sumper, A.; Cairo, I.; Cruz-Zambrano, M.; Vidal, N.; "Electric vehicles in power systems with distributed generation: Vehicle to Microgrid (V2M) project," Electrical Power Quality and Utilisation (EPQU), 2011 11th International Conference on , vol., no., pp.1-6, 17-19 Oct. 2011.

[16] Tremblay, O.; Dessaint, L.-A.; Dekkiche, A.-I.; , "A Generic Battery Model for the Dynamic Simulation of Hybrid Electric Vehicles," Vehicle Power and Propulsion Conference, 2007. VPPC 2007. IEEE, vol., no., pp.284-289, 9-12 Sept. 2007.

[17] Plan MOVELE, [http://www.movele.es], September 2012.

[18] Thirugnanam, K.; Saini, H.; Kumar, P.;, "Mathematical Modeling of Lion Battery for Charge/Discharge Rate and Capacity Fading Characteristics using Genetic Algorithm Approach," Transportation Electrification Conference and Expo (ITEC), 2012 IEEE

[19] Cleveland, F.M.; , "IEC 61850-7-420 communications standard for distributed energy resources (DER)," Power and Energy Society General Meeting - Conversion and Delivery of Electrical Energy in the 21st Century, 2008 IEEE, vol., no., pp.1-4, 20-24 July 